\title{
SLEUTELMAG EN AMP
}

Dr. P. J. Rossouw

\section{INLEIDING}

As die Heidelbergse Kategismus (Sondag 31) handel oor die sleutels van die Koninkryk, dan word die betrokkenheid van die ampte slegs per implikasie veronderstei ${ }^{1}$ ). Meer eksplisiet word die amp en sleutelmag in die Nederlandse Geloofsbelydenis gekoppel: "ons glo dat hierdie ware kerk ooreenkomstig die geestelike bestuurswyse wat ons Here ons in sy Woord geleer het, geregeer moet word ... hulle (moet) sorg dra dat die ware godsdiens onderhou (word), die ware leer orals versprei, die oortreders op geestelike wyse vermaan on in toom gehou (word) ..." (N.G.B. art. 30) en: "Ons glo verder dat die regeerders van die kerk, al is dit nuttig en goed om onder mekaar 'n bepaalde orde tot instandhouding van die liggaam van die kerk in te stel en te handhaaf, tog, noukeurig moet oppas om nie af te wyk van wat Christus, ons enigste Meester, vir ons ingestel het nie... Ons aanvaar derhalwe slegs wat kan dien om eendrag en eenheid te bewaar en te bevorder, en om alles in gehoorsaamheid van God te onderhou. Daarvoor is nodig die ban en alles wat daarmee saamhang, toegepas ooreenkomstig die Woord van God" (N.G.B. art. 32).

In die lig hiervan sal daar vervolgens stilgestaan word by die teksgedeelte wat hier van groot belang is, naamlik Matteus 16:19, asook die by die vraag na die verhouding tussen sleutelmag en volmag, sleutelmag en diakonia en laastens die verhouding tussen sleutelmag en amp.

\section{MATTEUS $16: 19$}

"Ek sal aan jou die sleutels van die Koninkryk van die hemel gee, en wat jy op aarde toeslust, sal in die hemel toegesluit bly; en wat jy op die aarde oopsluit, sal in die hemel oopgesluit bly."

\subsection{Herkoms}

Trimp wys daarop dat die gegewens in hierdie teks duidelike $\mathrm{Ou}$ Testamentiese wortels het. In Genesis vind ons dat Josef in Egipte aangestel is as die "eerste man" in die huis van Farao. As teken van hierdie besondere posisie ontvang hy die seëlring van Farao (Gn. 41 : 42). In die naam van Farao kan Josef bindende besluite neem (Trimp $1982: 143$ ). Voorts wys hy ook op die paleisbestuurder Sebna, en sy opvolger, Eljakim van wie in Jes. $22: 22$ gesê word: "En Ek sal die sleutel van die huis van Dawid op sy skouer lê; en hy sal oopmaak, en niemand sal sluit nie; en hy sal sluit, en niemand sal oopmaak nie" (vgl. Trimp $1982: 143)^{2}$ ).

\section{2 "Aan jou..." (Soi) (1)}

Op wie dui dit? Dui dit op Petrus, al die apostels of dalk die kerk? Om hierdie vraag te kan beantwoord, moet daar gekyk word na die konteks van Matteus 16:19, naamlik Matteus 16:13-20. In vers 16 vind ons die bekende belydenis van Petrus: " $U$ is die Christus, die Seun van die lewende God." Hierop antwoord Christus vir Petrus 
en van hierdie antwoord is vers 19 deel. Die "soi" dui dus (in die eerste plek, ten minste) op Petrus (Grosheide 1922: 198 e.vv.; Ridderbos $1946: 9$ e.vv.).

Dit word algemeen aanvaar dat Petrus opgetree het as die segsman van die apostels. In vele opsigte kan die bewering tereg gemaak word dat Petrus opgetree het as die "eerste" onder die apostels. $\mathrm{Na}$ die uitspreek van sy "belydenis", rig Jesus hierdie besondere woorde tot hom. Vers 19 dui dus eerstens op Petrus self (Zahn 1910: 549 e.vv.). Tog moet Petrus, sy persoon en sy belydenis, nie los gesien word van die heilshistoriese gebeure nie. Petrus was een van die apostels, 'n ampsdraer (Zahn 1910:549 e.vv.), deur Christus self tot apostel geroep. In aansluiting by Calvyn wys Trimp dan ook tereg op die volgende: 'Petrus' potestas is niet een eigenschap die inherent is aan of verklaar kan worden uit zijn eigen persoon, maar is een volmacht die haar rechtskracht ontleent aan Hem, die zelf de inhoud van het getuigenis is ..." (Trimp 1982:157; vgl. Calvin 1949 II : 290 e.vv.).

In hierdie verband is dit insiggewend om te let op die eksegese van Van Hartingsveld ten opsigte van Matteus $18: 18$. Hy praat van "sleuteldragers". Al word Petrus hier aangespreek moet 'n teks soos Ef. 2:20 nie uit die $00 \mathrm{~g}$ verloor word nie. Hiervolgens is die kerk op die fondament van die apostels en profete gebou - en hiermee stem Matteus 18:18 ooreen (Van Hartingsveld s.a.: 25,6) ${ }^{3}$ ).

\subsection{Sleutels ("kleidas")}

Uit Sondag 31, vraag en antwoord 83, van die Heidelbergse Kategismus kan die afleiding gemaak word dat daar twee sleutels onderskei kan word: die verkondiging van die evangelie en die Christelike ${ }^{4}$ ) tug. So 'n afleiding is egter té simplisties. Die verkondiging van die evangelie en die tug is nie as sodanig die twee sleutels nie alhoewel dit in die sleutelmag oor hierdie twee sake gaan. Dieselfde antwoord 83 praat van die twee sake as "handelinge". Onses insiens word die Kategismus oor-vra as daar gemeen word dat Sondag 31 die vraag na die hoeveelheid van dic sleutels limitatief beantwoord.

Tereg wys Trimp (1982:142) daarop dat die hoeveelheid sleutels nie af te lei is uit hierdie teks nie. Wat wel van belang is, is die feit dat Petrus "complete volmacht" (Trimp 1982:142) ontvang. As Trimp egter die benaming "sleutelbos" gebruik, impliseer dit, myns insiens, té eksplisiet dat daar beslis 'n hele aantal sleutels is (Trimp 1982: 142; Ridderbos $1946: 142$ ).

\subsection{Kerk en koninkryk}

Gaan dit in hierdie gedeelte oor die kerk, oor die koninkryk of val die twee saam (soos ons vind by die klassieke Rooms-Katolieke eksegese in die verband)? Wat is die verhouding tussen kerk en koninkryk in Matteus 16:19?

In sy kommentaar toon Groshede $(1922: 201)$ aan dat dit in vers 19 nie (meer) oor die "ekklēsia" gaan nie, maar oor die koninkryk van die hemele. Hierdie twee is nie gelyk nie en die verskil kom duidelik na vore in hierdie vers. Die inhoud van die prediking van Christus was die Koninkryk - nooit 'n organisasie, 'n kerk nie. Hier- 
đie vers toon egter ook die verband tussen die "ekklēsia" en die "basileia". Die koninkryk is die "ruimere": "Bij de ekkl. is sprake van het ontvangen van sleutels, d.w.z. het hebben van macht over iets .. de sleutels zelf zijn geen sleutels der ekkl.: maar van het k.d.h., ... de strekking van de sleutels is verder dan de ekkl., ze geven toegang tot of sluiten buiten het k.d.h..." (Grosheide $1922: 201)^{5}$ ).

Die uniekheid van die verhouding tussen kerk en koninkryk blyk duidelik uit bogenoemde opmerking van Grosheide. Nou verwant hieraan is die vraag wat die posisie van Petrus in die kerk en/of koninkryk is. Teenoor die standpunt van Calvyn (wat dit duidelik stel dat die één fondament van die kerk Jesus Christus is - vgl. 1 Kor. $3: 11$, Ef. $2: 20{ }^{\circ}$ ), beweer van Hartingsveld: "Petrus is niet alleen fundament van de gemeente van Jezus Christus, maar ook de sleuteldrager van het Koninkrijk Gods" (Van Hartingsveld s.a. : 23). In die verband beweer Trimp $(1982: 148,9)$ ook: "De weg van God naar zijn wereld loopt via Jezus van Nazareth, zijn discipel Petrus en zijn kerk. die Hij gaat bouwen ... Dáárom zal niemand buiten Petrus om dit rijk kunnen binnegaan en in dat rijk kunnen leven" ').

Om egter 'n duidelike antwoord op die posisie van Petrus te vind, moet die organiese eenheid van hierdie teks met die res van die perikoop die Matteus-evangelie, die sinoptici, die Nuwe Testament en uiteindelik die hele Skrif, steeds voor oë gehou word. In die lig hiervan is dit duidelik dat daar nie van 'n primaatskap van Petrus gepraat kan word nie en dat ons heel versigtig moet wees vir konklusies ten opsigte van 'n unieke "heils-posisie" van die persoon van Petrus. Die verhouding tussen kerk en koninkryk en die posisie van Petrus bepaal/beīnvloed mekaar wedersyds in Matteus 16:19 (Grosheide 1922 : 201; Gründmann 1968 : 387 e.vv.; Hahn $1977: 539$ e.vv.).

\subsection{Oopsluit en toesluit}

In sy Institusie betrek Calvyn (1931 IV, xi, 1) die oop- en toesluit op die Woordbediening: "Dit gebod over vergeven en houden der zonden en die aan Petrus gedane belofte over het binden en ontbinden moeten nergens anders op betrokken worden dan op den dienst des woords welke de Heere aan de apostelen zoo toevertrouwde, dat Hij hen tegelijkertijd toerustte met dit ambt van ontbinden en binden" ${ }^{8)}$.

Dic woorde "dēsēs/dedemenon" en "lusẹs/lelumenon" is Joodsrabbynse begrippe wat deur Skrifgeleerdes en Wetgeleerdes gebruik is om bindende uitsprake te maak oor die uitleg en toepassing van die tora (Strack en Billerbeck 1922: 738 e.vv.). Tereg toon Nielsen $(1973: 85)$ aan dat dit nie hier om 'n konkrete geval gaan nie, maar om "n heel algemene. Jesus se interpretasie van die "tradisionele" binding hou egter ook 'n tweede perspektief in. Petrus het ook die mag om te ontbind/ontsluit.

Die kategismus lê klem op twee fasette van die oop- en toesluit, naamlik die verkondiging van die evangelie en die tug. Die oopsluit van die koninkryk deur die evangelie geskied deur genadeverkondiging aan die gelowiges (gesamentlik en afsonderlik) en die toesluit deur die retensie aan ongelowiges. Die toesluit van die koninkryk deur die tug vind piaas deur die uitsluiting van diegene wat volhard 
in die sonde en die oopsluit geskied deur die belofte én bewys van "verbetering".

2.6 "Aan jou..." (2)

In die lig van die voorafgaande eksegetiese opmerkinge word daar weer eens aandag bestee aan die betekenis van die "soi" (aan jou). Opvattinge (in die gereformeerde tradisie) oor die betekenis hiervan, val in drie groepe uiteen.

2.6.1 Apostels - kerk: Die eerste groep huldig die opvatting dat die "soi" op al die apostels dui en, deur hulle, ook op die kerk. Dit is die standpunt van (o.a.) H. N. Ridderbos en L. van Hartingsveld.

In sy kommentaar op Matteus beweer Ridderbos $(1946: 13,14)$ dat die volmag van Petrus implisiet die ander dissipels insluit. Voorts trek hy 'n direkte verband tussen die volmag van die apostels en die sleutelmag van die gemeente (Ridderbos 1946 : 13, 14). Van Hartingsveld wys ook daarop dat die "soi" op al die apostels dui: "Het ligt voor de hand dat men aan de apostelen gedacht heeft. De bevoegdheid, die aan Petrus verleend is, wordt nu ook aan de andere apostelen toebedeeld" (Van Hartingsveld s.a. : 25). Hy wys daarop dat die vers te gemaklik geīsoleer word van waaruit daar dan gekonkludeer word dat ons hier 'n sleutelmag het wat alleen aan die apostels toevertrou was: "We hebben geen losse teksten. We hebben alleen teksten in een bepaalde samenhang. En als we de kontekst mee laten spreken, is het duidelijk. dat de sleutels aan de gemeente gegeven zijn" (Van Hartingsveld s.a. : 26).

2.6.2 Petrus - apostels: Die tweede groep huldig die opvatting dat die "soi" alleen op Petrus en die apostels dui. Hier let ons op die standpunt van F. W. Grosheide. Hy beweer dat die woorde wat Jesus hier tot Petrus rig nie op alle gemeentelede of alle ampsdraers van toepassing is nie, maar alleen op die apostels: " $\mathrm{Zij}$ ontvangen openbaringen ter leiding der ekkl., wij zijn aan hun openbaringen, in de Schrift geboekstaafd, gebonden. Het uit het k.d.h. sluiten, zoowel als het ongeoorloofd verklaren dient te geschieden naar de door de apostelen gegeven regels" (Grosheide 1922:202).

2.6.3 Petrus - apostels ... - kerk: Die derde groep huldig die opvatting dat die "soi" primêr op Petrus dui en voorts dat dit $\delta \delta \mathrm{k}$ apostels betrek. Telkens word (gewoonlik by die gevolgtrekking) die kerk egter ook by hierdie sleutelmag van Petrus betrek. Dit is die benadering van (o.a.) Nielsen en Trimp.

Nielsen wys daarop dat die heilshistoriese posisie van Petrus uniek is en die sleutelmag, wat aan hom verleen word, onoordraag. baar: "met geen woord wordt over een dergelijke overdracht in de verzen 17-19 gesproken" (Nielsen 1973:86). Tog wys Nielsen daarop dat dit "onjuist" sou wees om enige eksklusiwiteit aan Petrus toe te ken. Hy en Paulus werk as gelykes saam in die eerste gemeente (Nielsen $1973: 80$ ).

Die ekwivalent van hierdie standpunt vind ons ook by C. Trimp. In die eerste plek wys hy (verskeie kere) op die unieke posisie van Petrus: Hy is die vernaamste kneg van Christus (Trimp 1982:142), 
die kontak tussen Christus en die volk word deur Petrus moontlik gemaak of beëindig (Trimp 1982:142), hy word aangestel as "oikonomos" en ontvang absolute volmag (Trimp $1982: 145$ ), sy persoon ontvang 'n sleutelposisie in die koninkryk van die hemel (Trimp 1982 : 148); "Daarom zal niemand buiten Petrus om dit rijk kunnen binnengaan en in dat rijk kunnen leven. Hij heeft als belijder van Christus en prediker van het in Christus geopenbaarde heil de sleutelpositie. Christus zelf bekleedt het in Mat. 16:19a met deze volmacht. De ontsluiting van de weg die tot de schatkamer van dat rijk leidt, komt geheel in de macht van deze discipel van Christus" (Trimp 1982:148).

Tog maak Trimp in sy konklusie die (verrassende) opmerking: "Tegelijk bevestigen deze woorden (Mt 16:18, 19 - P. J. R.) van Christus, dat Petrus wél de eerste maar niet de enige sleuteldrager zal zijn. Het fundament van de kerk is breder dan de ene (rots) steen Petrus, zoals ons ook in Ef. $2: 20$ en Openb. $21: 14$ wordt geleerd" (Trimp $1982: 158$ ).

\subsubsection{Gevolgtrekking: Petrus - apostels - kerk}

Vervolgens word ' $n$ eie keuse gemaak. Elk van bogenoemde standpunte word nie hier afsonderlik bespreek of beoordeel nie. In die eie keuse kom die kritiek en winsmomente van die onderskeie standpunte implisiet na vore. Teenoor die drie genoemde standpunte kies ons vir 'n standpunt wat as Petrus - apostels - kerk voorgestel kan word. Hiervolgens word daar ten opsigte van die sleutelmag 'n logiese verband tussen die apostel Petrus, die ander apostels en die kerk van Christus getrek. Met hierdie standpunt word daar aangesluit by die benadering van Calvyn.

a Petrus: Calvyn toon tereg aan dat Christus hier primêr vir Petrus aanspreek. Hy doen dit in die lig van die genoemde belydenis van Petrus. Voorts is dit ook begryplik uit hoofde van die feit dat Petrus die eerste/segsman van die apostels was (Calvin 1949 II : 296 e.vv.). Die uitspraak ten opsigte van die sleutelmag geld dus in die eerste plek, primèr, ten opsigte van Petrus. Van die hantering van die sleutelmag deur Petrus lees ons ook telkens in die boek Handelinge (vgl. Hd. 2 : 14 e.vv.; Hd. 3, 4, 5, 9. 10, 11, 15).

b Apostels: Calvyn wys ook op die noue verband tussen Petrus en die ander apostels. Hy wys daarop dat Petrus se "seggenskapsposisie" beslis nie 'n unieke uitsonderingsposisie is wat inhou dat hy verhef was bo die ander apostels nie (Calvin $1949 \Pi$ : 296). Trouens, die "deelname" van die apostels aan die sleutelmaguitspraak van Christus word (in mindere of meerdere mate) nie deur een van genoemde drie groepe betwyfel nie. So vind ons in die boek Handelinge ook talle bewyse van die uitoefening van die sleutelmag deur die apostel Paulus.

c Kerk: Calvyn wys egter ook op die noue verband van die sleutelmag met die kerk. Hy wys daarop dat die apostels: "were at first nothing more than temporary preachers, and so, when they returned to Christ, they had executed their commission; but after that Christ had risen from the dead, they then began to be appointed to 
be ordinary teachers of the Church" (Calvin 1949 II . 293). Hiervolgens is die sleutelmag nie iets unieks verbonde aan die persoon van Petrus of alleen aan die (tydelike) amp van apostel nie, maar 'n inherente deel van die (amptelike) organisasie van die kerk - hiervan getuig die boek Handelinge oorvloediglik.

d Sleutelmag van die kerk: Tereg fundeer die Kategismus die sleutelmag van die kerk (o.a.) in Matteus 16:19. Hierdie fundering vind ons (o.a.) ook by Calvyn ${ }^{9}$ ), Van 't Spijker ${ }^{10}$ ), Kamphuis ${ }^{11}$ ), Van Hartingsveld ${ }^{12}$ ), en die kerkorde (Jensen 1952 : 310 e.vv.; Bouwman 1932 II : 27 e.vv.).

\section{SLEUTELMAG EN VOLMAG}

Nou verwant aan die begrip "sleutelmag" is die begrip "volmag". Hierdie volmag vind sy oorsprong in die volmag van Jesus. Laasgenoemde volmag se oorsprong lê in die sending van Jesus deur die Vader. Hy is deur die Vader gestuur as die Middelaar en Verlosser (H.K. Sondag 5, 6 en 7) wat die heil van God verkondig en Self ook die inhoud van die heil is.

Die volmag van Jesus blyk regdeur sy aardse lewe, vanaf sy doop in die Jordaan (Mk 1:9-11), in sy leer (Mk $1: 22)$, sy mag oor die bose magte en ander wonders (Mk $1: 23-27$ ), die vergewing van sondes (Mk $2: 10$ ), en oordeelsaankondiging (Mk 13) (H.K. Sondag 5,6 en 7 , vgl. Intercommunie en Ambt $1976: 11$ ).

As Christus die sleutelmag aan Petrus toevertrou, sluit dit ook volmag in (vgl. die eksegese van Mtt 16:19). Die volmag van Petrus - apostels - kerk is egter nie dieselfde as die volmag van Christus nie. Die volmag van Christus is uniek/onherhaalbaar, persoon- en werkgebonde en ewig. Die volmag van Petrus, daarenteen, is 'n "beperkte volmag"; dit is 'n volmag om die sleutels te hanteer en geen onafhanklike of volstrekte mag nie.

Hierdie volmag om die sleutels te hanteer staan altyd in die teken van 'n maatstaf, 'n toetssteen. Hierdie toetssteen is die Woord wat onlosmaaklik aan die Seun van God verbind is. In hierdie verband merk Calvyn dan ook op: "Want Christus heeft deze macht eigenlijk niet aan de mensen gegeven, maar aan zijn Woord, tot welks dienaren Hij de mensen gemaakt heeft" (Calvijn $1931 \mathrm{IV}, \mathrm{xi}, 1$ ).

Jesus Christus beklee vir Petrus met die volmag om die sleutels te bedien; ' $n$ volmag wat telkens getoets moet word aan die Woord.

Hierdie volmag blyk duidelik in die tweërlei "handelinge" by die gebruik van die sleutels. Eerstens dui die volmag op 'n volmag om die evangelie te verkondig. Sodanig is die volmag dat die "sleuteldraer" die koninkryk van die hemel deur die verkondiging oop en toe kan sluit.

In sy rede: "De volmacht tot bediening der verzoening", wys Trimp (1970:7 e.vv.) op die volmag in die hantering van hierdic sleutel. Hy wys daarop dat dit in die volmag tot die bediening van die versoening om 'n amptelike handeling gaan (Trimp $1970: 7$ e.vv.). Hierdie amptelike handeling geld ten opsigte van die openbare erediens sowel as die afsonderlike verkondiging van die evangelie (H.K. Sondag 31). Die inhoud van die verkondiging behels die verkondiging 
van vergiffenis van sonde op grond van die verdienste van Christus as dié belofte van die evangelie met ' $n$ ware geloof aangeneem word (H.K. Sondag 31)

Voorts behels die verkondiging van die evangelie ook die aankondiging van die toorn van God en die ewige verdoemenis aan diegene wat hulle nie bekeer nie (H.K. Sondag 31). Tot hierdie verkondiging het die ampsdraer volmag. Alle verkondiging wat nie hiermee strook nie, en dus ook nie in ooreenstemming met die Woord van God is nie, is verwerplik en het as sodanig géen volmag nie.

Die volmag van die sleutels behels tweedens ook 'n volmag om die koninkryk deur die tug toe en oop te sluit. Ook hier het ons te doen met ' $n$ amptelike handeling (Kamphuis 1982:53 e.vv.; Van 't Spijker $1982: 78$ e.vv.) waarvolgens diegene wat die naam Christen dra en hulle tog onchristelik en onbetaamlik gedra én daarin volhard sonder berou. uit die ryk van Christus uitgesluit word (H.K. Sondag 31). Met hierdie sleutel kan die ryk van Christus ook weer oopgesluit word vir diegene wat berou toon en "werklike verbetering beloof en bewys" (H.K. Sondag 31).

Dit is belangrik om ook hier daarop te wys dat die volmag tot die hantering van hierdie sleutel slegs geld waar die Woord van God as enigste rigtinggewende maatstaf gebruik word.

\section{SLEUTELMAG AS DIAKONIA}

\subsection{Sleutelmag as diens?}

Is dit legitiem om te beweer dat die wese van die sleutelmag "diens" is? Hierdie standpunt kry ons by (o.a.) M. Nel. Hy beweer (in aansluiting by W. D. Jonker). "Selfs die sleutelmag van die ampte in die handhawing van die kerklike tug is nie soseer 'n mag nie, maar 'n diens van die Koning" (Nel 1982 : 17; vgl. Bijlsma 1981 : 114 e.vv.). Ietwat verwarrend is die afwisselende gebruik van "diakonia" en "diens" by B. Wentsel. Ten opsigte van die sleutels merk hy op: "De dienst der sleutels functioneert vervolgens als een troostrijke bemoediging voor verdrukten en als een verzekerende aansporing voor bekommerden en twijfelenden" (Wentsel $1981: 369$ ).

Oor die vertaling van "diakonia" as "diens" kan daar lank gediskusseer word. As onder "diens" die verenigde visie op die "diakonia" verstaan word, dan is dit duidelik dat die sleutelmag nie as 'n "diens" gesien kan word nie, aangesien dit die volmag van die sleutelmag ondermyn. Dit hou dus 'n gevaar in om van die "diens" van die sleutelmag te praat. Die gevaar van veroppervlakkiging in die hantering van die sleutels as daar van "diens" gepraat word, moet nie onderskat word nie

\subsection{Sleutelmag as diakonia}

Tereg praat Trimp (1982a : 168 e.vv.) in aansluiting by Calvyn, van die "bediening" van die sleutels. Wentsel omskryf die diakonia van die sleutelmag treffend as hy skryf: "De diakonia van de sleutels (de sleutelmacht) is de bevoegdheid of volmacht om het rijk Gods voor gelovigen voor geopend en voor verharden voor gesloten te verklaren. Deze volmacht is door Christus geschonken aan de apostelen als vertegenwoordigers van de gehele gemeente en als verte- 
genwoordigers van de Zender... Deze diakonia houdt ook in het dringend appèl tot geloof en ommekeer met het oog op het voor eeuwig verloren kunnen gaan" (Wentsel $1981: 369$ ).

So vind die sleutelmag sy uitdrukkingswyse - in die diakonia. Hierdie diakonia bepaal die wyse en karakter van die sleutelmag en tas ook nie die eie aard van die sleutelmag, naamlik die oop-en toesluit van die koninkryk en die volmag daartoe, aan nie.

\section{SLEUTELMAG, AMP EN GESAG}

In die voorafgaande bespreking oor die sleutelmag het die noue verhouding tussen sleutelmag en amp reeds duidelik na vore gekom (vgl. Calvin $1949 \mathrm{II}: 293$ ). Dit is laastens egter belangrik om iets op te merk oor die verhouding tussen die sleutelmag, amp en gesag.

Oor die gesag van die amp is dikwels geskryf ${ }^{13}$ ). Noordegraaf wys tereg daarop dat gesag dikwels gesien word as 'n bedreiging vir inspraak, mondigheid en medeseggenskap (Noordegraaf 1980:148 e.vv.). Die gesag van die amp moet altyd in noue verhouding met die volmag van die sleutelmag gesien word. Los van die sleutelmag kan daar geen sprake van volmag wees nie en dus ook geen gesag by die amp nie.

Ons kan dit 'n stap verder voer: Los van die Woord bestaan daar geen sleutelmag, geen volmag, geen gesag en geen amp nie. Gesag mag nooit as 'n eienskap van die amp as sodanig, los van die sleutelmag gesien word nie. Gesag is wel 'n inherente eienskap van die sleutelmag, maar die sleutelmag word telkens begrens deur die Woord van God.

Die ampte (van bedienaar van die Woord en ouderling) is beklee met gesag omdat hierdie ampte verantwoordelik is vir die hantering van die sleutels. In hierdie sin het die amp van diaken geen gesag nie aangesien dit buite sy taak val om die sleutels te hanteer. Hiermee word daar nie beweer dat 'n uiters belangrike saak soos die onderlinge vermaning alleen die taak van bogenoemde twee ampte is nie. Die onderlinge vermaning is van groot belang in die gemeente. Ons volstaan dus nou deur slegs daarop te wys dat die onderlinge vermaning die taak van elke Christen is.

Dit is belangrik om daarop te wys dat die gesag wat hier ter sprake is nie verwar moet word met die sekulêre gebruik en voorkoms van die begrip "gesag" nie. Die kerklike gesag is gesag wat verbonde is; verbonde aan die oop- en toesluit van die koninkryk van die hemel. Dit is dus 'n gesag wat voortvloei uit die volmag om die sleutels te hanteer. Hierdie volmag het Christus Sélf aan Petrus verleen. Hierdle gesag het dus niks in gemeen met begrippe soos "heerskappy", "heerssug", "oorheersing" en "magsuitvoering" nie. Die gesag van die amp dra altyd die karakter van die diakomia - 'n diakonia van die Woord as opdrag van die groot diakonos, Jesus Christus.

\section{Voetnotas}

1. "Vraag 83: Wat is die sleutels van die koninkryk van die hemel? Antw.: Die verkondiging van die Evangelie en die Christelike tug. Met albei hier- 
die handelinge word die koninkryk van die hemel vir die gelowiges oopgesluit en vir die ongelowiges toegesluit". Vraag en antwoord 84 handel oor die oop-en toesluit van die koninkryk deur die verkondiging van die Evangelie, en vraag en antwoord 85 oor die tug (vgl. De Vries en Wentsel $1979: 116,7)$.

2. Al is hier bepaalde lyne van ooreenkoms te trek, moet die belangrike feit egter steeds voor oë gehou word dat ons hier met 'n unieke gebeure te doen het.

3. Ook Nielsen beweer in hierdie verband: "Het gat in vers $18 \mathrm{~b}$ inderdaad om Petrus als belijdend mens. Maar de exclusiviteit die Petrus wil los. maken van de andere discipelen, vind in vers $18 \mathrm{~b}$ geen steun" (Nielsen 1973 II : 801).

4. Ons gaan nie hier op die verskil van die nuwe vertaling van die belyde nisse (1982) met die van die ou vertaling in nie. Dit is egter insiggewend om daarop te let dat die vorige vertalings (soos trouens die meeste Nederlandse vertalings - vgl. die vertaling van die Gereformeerde Kerken in Nederland - Vrijgemaakt - 1975) hier soos volg lui: "Die verkondiging van die heilige evangelie en die kerklike tug.

5. Vergelyk Ridderbos wat in dieselfde trant beweer: "De gemeente is immers de vergadering dergenen die het koninkrijk verwachten en het heil van het koninkrijk in dit en het toekomstige leven ontvangen" (Ridderbos $1946: 13$ ).

6. “... it can be nothing less than blasphemy and sacrilege, when the Pope has contrived another foundation" (Calvin 1949 II :295, 6).

7. Tog kan daar nie noodwendig beweer word dat Trimp Petrus as die fondament van die kerk sien nie. In die verband wys hy immers op die volgende: “... Niemand kan dáánaast een ander fundament leggen (vgl. 1 Kor. 3:11). Petrus en de apostelen worden de leraars van het Nieuwe Verbond" (Trimp $1982: 149$ ).

8. Tog le Calvyn ook deurgans in sy institusie klem op die tug as amptelike sleutelmaghantering van die kerk (vgl. IV, xi, 1 e.vv.; $I V$, xii, 1, 6, 22).

9. Vgl. Calvijn 1931 IV, i. 22; "Want toen Christus aan de apostelen bevel gegeven heeft en macht verleend om de zonden te vergeven (Matth. 16: $1918: 18$; Joh. $20: 23$ ). heeft Hij niet aheen gewild, dat zij diegenen ontbinden zouden van de zonden, die zich van hun goddeloosheid tot het geloof in Christus bekeerden, maar veeleer dat ze dit ambt voortdurend onder de gelovigen zouden bedienen" (Calvijn 1931 IV, xi, 1e.vv; IV, xii, 1, 6, 22).

10. (Van 't Spijker $1982: 71$ e.vv.). In hierdie verband maak hy die volgende insiggewende opmerking: “Opmerkelijk is, dat het gereformeerde ideaal van meetaf vasstond. dat het ook in zijn methode duidelijk omschreven werd in aansluiting aan Matt. 16 en 18, en ook dat het sindsdien vrijwel onveranderd van de ene kerkorde in de andere werd opgenomen. Geén deel van de gereformeerde kerkorde was aan zo weinig verandering onderhevig, als dat deel, dat over de tucht zich uitspreekt" (Van 't Spijker $1982: 94)$.

11. (Kamphuis $1982: 24$ e.vv.). In aansluiting by die Kategismus (So. 31) onderskei Kamphuis ook twee sleutels: Die vermaning en bestraffing van die prediking (eerste sleutel) en die tug (tweede sleutel). Hierdie sleutel- 
mag koppel' hy dan ook direk aan die kerklike praktyk (Kamphuis 1982 : 25 e.vv.).

12. (Van Hartingsveld s.a. : 63, 4). Hy wys op die verband van die tekste; Matt 16:19 met 16:19 met Mtt 18 en ook ander belangrike gegewens in die Nuwe Testament in dié verband. Volgens hom pleit die teksverband (vgl. veral Mt 18) téén 'n beperking van die sleutelmag alleen tot Petrus of die apostels en hy konkludeer dan tereg: "Gegeven de kontekst zijn de sleutels van het Koninkrijk der hemelen aan de gemeente toevertrouwd" (Van Hartingsveld s.a.: 63, 4).

13. Van Ruler 1971 : $\$$ e.vv.; Ridderbos $1969: 159$ e.vv.; Noordegraaf $1980: 147$ e.vv.; Sietsma 1945:66 e.vv.; Nel 1982:17; Jonker 1970:6 e.vv.; Trimp 1982 : 138 e.vv.; Ridderbos 1966 : 528 e.vv.

Lys van aangehaalde werke.

Bouwman, H. 1932. Gereformeerde kerkrecht 1 \& 11. Kampen: Kok.

Bijlsma, R. 1981. Toch gemeente. Kampen: Kok.

Calvin, J. 1949. Commentary on a harmony of the evangelists, Matthew, Mark and Luke 1, 11 \& 111. (Translated by W. Pringle). Grand Rapids: Ferdmans.

Calvijn, J. 1931. Institutie of onderwljzing in den Christelijken godsdienst 1, 11 \& 111. (Vertaald door A. Sizoo). Delft. Meinema.

Grosheide, F. W. 1922. Het heilig evangelle volgens Mattheus. Amsterdam: Van Bottenburg.

Grundmann. W. 1968. Das Evangelium nach Matthäus. Berlin: Evangelische Verlaagsanstalt.

Hahn, F. 1977. Die Petrusverheissung. Mtt 16, 18f, in: Kertelge, K. Das Kirchliche Amt im Neuen Testament. Darmstadt: Wissenschaftliche Buchgesellschaft.

Intercommunie en ambt. Bijbelse achtergronden en perspectiven. 1976. 's-Gravenhage: Boekencentrum.

Jansen, J. 1952. Korte verklaring van de kerkorde der Gereformeerde Kerken. 3de uitgawe. Kampen: Kok.

Jonker, W. D. 1970. Als een riet in de wind... Een pelling van het theologische karakter van de diakoniologische vakken. Kampen: Kok.

Kamphuis, J. 1982. Om de hefligheld van de gemeente. De kerkelijke tucht. Kampen: Van den Berg.

Nel, M. 1982. Jeug en evangelle. Pretoria: NG Kerkboekhandel.

Nielsen, J. T. 1973. Het evangelie naar Mattheüs 11. Nijkerk: Callenbach.

Noordegraaf, A. 1980. Gods bouwerk. Aspecten van het gemeente-zijn in bijbels-theologisch licht. 's-Gravenhage: Boekencentrum.

Ridderbos, H. 1966. Paulus. Een ontwerp van zljn theologle. Kampen: Kok.

Ridderbos, H. N. 1946. Het evangelie naar Mattheüs. Kampen: Kok.

Ridderbos, H. N. 1969. Gezag en ambt, in: Rondom het Woord $11: 159-74$. 
Sietsma, K. 1945. De Ambtsgedachte. Amsterdam: Bakker.

Strack, H. L. \& P. Billerbeck 1922. Das Evangelium nach Matthäus. München: C. H. Beck'sche Verlagsbuchhandlung.

Trimp, C. 1970. De volmacht tot bediening der verzoening. Groningen: De Vuurbaak.

Trimp, C. 1982. Ministerium. Een introductie in de reformatorische leer van het ambt. Groningen: De Vuurbaak.

Van Hartingsveld, L. s.a. De sleutels van het koninkrijk der hemelen. Kampen: Kok.

Van Ruller, A. A. 1971 Theologische werk 11 \& 111. Nijkerk: Callenbach.

Van 't Spijker, W. 1992. De ouderling en zijn werk in het licht van de kerkorde, in: Koole, D. \& Velema W. H. (red.). Uit liefde tot Christus en zijn kerk. Handleiding aan de ouderling. Kampen: Kok.

Wentsel, B. 1981. Het Woord, de Zoon en de dienst. Dogmatiek deel 1. Kampen: Kok.

Zahn, I. 1910. Das Evangelium des Matthäus. Leipzig: Deichert'sche Verlagsbuchhandlung. 